\title{
Editorial
}

Published online: March 15, 2012

DOI: 10.1159/000335711

\section{Techniques of Liver Resection}

\author{
Thomas M. van Gulik ${ }^{a} \quad$ Wolf O. Bechstein ${ }^{b}$ \\ ${ }^{\mathrm{a}}$ Department of Surgery, Academic Medical Center, Amsterdam, The Netherlands; ${ }^{\mathrm{b}}$ Department of Surgery, \\ Goethe University Hospital, Frankfurt am Main, Germany
}

Liver resections can be performed with low morbidity and minimal mortality owing to improved preoperative assessment and the use of established surgical techniques. Right or left hemihepatectomy has become a standardized surgical procedure, whereas at the same time, we prefer to carry out parenchyma-sparing resections on the (sub)segmental level, especially in livers with concurrent parenchymal liver disease. Laparoscopic liver resections are increasing and in combination with ERAS programs are associated with shorter hospital stay. This thematic issue of Digestive Surgery is devoted to some of the current techniques of liver resection as they have evolved in the past years, and the management of the most common complications associated with liver resection.

When planning liver resection, the volume and functional reserve of the remnant liver are crucial to performing a safe resection. How much remnant liver is enough remains the key question, especially in compromised livers such as in liver cirrhosis, steatosis and not unimportantly, after chemotherapy. The anterior intrahepatic approach with mass stapling of the right portal vein in right hemihepatectomy has the advantage of preserving as much parenchyma as possible. When the future remnant liver proves too small, preoperative portal vein embolization is a viable option to increase remnant liver volume. Particularly in patients with advanced biliary cancer and cholestatic livers, preoperative portal vein embolization is an advantage and it increases the success of resection.

There are several techniques for transection of the liver parenchyma and for clamping of the afferent vessels at the hepatic pedicle, mainly aiming at limiting blood loss during resection. The clamp-crushing technique is the time-honored mainstay of parenchymal dissection and there is no solid evidence that outcomes are improved by using newer methods or devices. Bipolar radiofrequency in parenchymal transection of the liver is a promising method to reduce blood loss during liver resection. This technique has now been in use for several years and awaits further clinical assessment. Vascular occlusive techniques such as the Pringle maneuver can be used to reduce blood loss. In complex liver resections or when anticipating prolonged vascular inflow occlusion, intermittent application of the Pringle maneuver is advised.

Bile leakage is a troublesome complication after liver resection which is effectively treated by percutaneous or endoscopic biliary stenting. The use of fibrin sealants to achieve hemostasis after liver resection remains popular, although there is no evidence that fibrin sealants reduce postoperative resection surface-related complications.

The indications for laparoscopic liver resection are expanding but require additional training, both in liver surgery and laparoscopic surgery. On behalf of the Dutch Study Group for Liver Surgery in the Netherlands, a trial on laparoscopic liver resection has been launched. Whatever the technique applied in liver resection, the most difficult event to manage is postresectional liver failure. All our perioperative efforts should therefore be directed to prevention of this potentially lethal complication.

These topics have been discussed during a symposium held in Amsterdam on March 25, 2011. We are very pleased that most of the speakers who joined this symposium have contributed to this special issue dealing with techniques of liver resection.

\begin{tabular}{ll}
\hline KARGER & @ 2012 S. Karger AG, Basel \\
Fax +41613061234 & $0253-4886 / 12 / 0291-0005 \$ 38.00 / 0$ \\
$\begin{array}{l}\text { E-Mail karger@karger.ch } \\
\text { www.karger.com }\end{array}$ & $\begin{array}{l}\text { Accessible online at: } \\
\text { www.karger.com/dsu }\end{array}$
\end{tabular}

